\title{
Apoptosis to predict copepod mortality: state of the art and future perspectives
}

\author{
I. Buttino - J.-S. Hwang - C.-K. Sun · C.-T. Hsieh • \\ T.-M. Liu • D. Pellegrini $\cdot$ A. Ianora $\cdot$ D. Sartori $\cdot$ \\ G. Romano $\cdot$ S.-H. Cheng $\cdot$ A. Miralto
}

Published online: 5 November 2010

(C) Springer Science+Business Media B.V. 2010

\begin{abstract}
Apoptosis or programmed cell death is the result of complex biochemical and genetic signals triggered by normal physiological events or by exposure to toxic compounds. Apoptosis can be revealed early in cells and tissues due to morphological and biochemical alterations of the cell. Here, we review recent progress in the study of the induction
\end{abstract}

Guest editors: J.-S. Hwang and K. Martens / Zooplankton Behavior and Ecology

I. Buttino $(\bowtie) \cdot A$. Ianora · G. Romano - A. Miralto Stazione Zoologica Anton Dohrn, Villa Comunale, 80121 Napoli, Italy

e-mail: buttino@szn.it

I. Buttino · D. Pellegrini · D. Sartori ISPRA Istituto Superiore per la Protezione e Ricerca Ambientale, Viale Nazario Sauro, 4, 57128 Livorno, Italy

J.-S. Hwang

Institute of Marine Biology, National Taiwan Ocean

University, Keelung, Taiwan

C.-K. Sun

Department of Electrical Engineering, National Taiwan University, Taipei, Taiwan

C.-T. Hsieh · T.-M. Liu

Institute of Biomedical Engineering, National Taiwan

University, Taipei 10617, Taiwan

\section{S.-H. Cheng}

Tungkang Biotechnology Research Center, Fisheries

Research Institute, Tungkang, Pingtung, Taiwan and detection of apoptosis in zooplankton copepods after their exposure to different apoptotic-inducer compounds, and we propose methods to predict copepod mortality even when animals appear normal. We also discuss the use of higher harmonic generation microscopy and multiphoton fluorescence microscopy techniques as possible tools to visualize apoptosis in vivo copepods without using any fluorescent probes.

Keywords Confocal microscopy $\cdot$ Harmonic generation microscopy · Fluorescent probes · Necrosis

\section{Introduction}

Since the first studies demonstrating that certain diatom diets negatively impact copepod egg hatching success and larval development over a decade ago (Ianora \& Poulet, 1993; Poulet et al., 1994; Miralto et al., 1999), with consequences for energy flow rates through the marine food chain (reviewed by Ianora et al., 2003; Pohnert et al., 2007; Caldwell 2009), there has been increasing awareness of the need to identify specific tools able to predict embryo or naupliar mortality (Poulet et al., 2003; Buttino et al., 2004).

Egg viability has been considered a realistic index of population recruitment rates at sea (Miralto et al., 2003). However, eggs may hatch into strongly deformed nauplii (e.g. Ianora et al., 2004). Hence 
the questions of how long nauplii survive and whether they contribute to population recruitment rates at sea remains unresolved.

The identification of active programmed cell death in copepods opens new and unexpected possibilities to predict embryo and naupliar viability in zooplankton communities. Since some apparently normal copepod embryos or deformed nauplii are positive for apoptotic markers (Buttino et al., 2003, 2004; Romano et al., 2003), the possibility to predict egg, naupliar or adult mortality appears realistic.

Apoptosis or programmed cell death (PCD) is well-established in unicellular organisms (Depont, 2008; Hamman et al., 2008) and in metazoan animals (Jacobson et al., 1997) and plants (Gadjev et al., 2008). Apoptosis is determined by precise, genetic, and molecular induction (Williams, 1991), triggered by physiological events such as metamorphosis in amphibians and fetal development in mammals, or by external factors such as exposure to toxic compounds or to environmental stress (Rastogi et al., 2009).

Apoptotic processes are revealed early in cells, tissues, and organs due to certain peculiar characteristic events inducing morphological and biochemical alterations (see Krysko et al., 2008 for a review) such as cell shrinkage, nuclear blebbing, and condensation, with formation of membrane bound-vesicles called apoptotic bodies. Alteration of DNA with consequent fragmentation and degradation and the inversion of plasma membrane permeability, coupled with exposure of phosphatidyl serine residues at the cell surface, are other morphological events common to apoptosis in many biological systems (Fig. 1).

Specific biochemical and molecular signals begin with cascades of events including activation of cysteine-dependent proteases (caspases in mammals or cysteine protease-homologs in non-mammals) (Yuan et al., 1993), and release of cytochrome $c$ from the mitochondrial inter-membrane space to the cytosol. Activation of hundreds of proteins is involved as part of an extremely fine-tuned regulatory network consisting of pro- and anti-apoptotic factors.

These specific events differentiate apoptosis from necrosis; the latter generally occurs when cells are exposed to extreme conditions which may result in damage to the plasma membrane, and begins with an impairment of the cell's ability to maintain homeostasis. As a consequence, an influx of water and extracellular ions lead to cell swelling and rupture

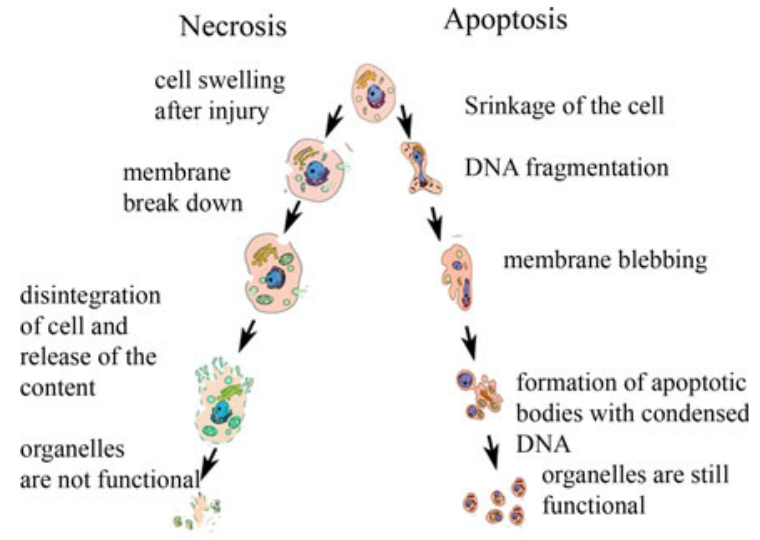

Fig. 1 Schematic representation of necrotic and apoptotic cells. In the figure are resumed the most evident modifications, induced by the two different processes, occurring into the cell (by http://anatomy.iupui.edu, modified)

(cell lysis) with the release of cytoplasmic contents into the extracellular fluid. Therefore, in vivo, necrotic cell death is often associated with extensive tissue damage resulting in an intense inflammatory response (Fig. 1). Generally, apoptosis and necrosis follow a temporal sequence with necrosis succeeding apoptosis but often the intensity of the initial insult decides for the prevalence of one process rather than the other (Behilarz et al., 1995; Leist \& Nicotera 1997).

The interest in studying apoptotic responses in vertebrates is due to the role that PCD has in generating different pathologies or degenerative diseases (Krysko et al., 2008; Rastogi et al., 2009). The complexity of events inducing apoptosis in pluricellular organisms and the significance of different modes of death are under continuous investigation, especially in human pathology where the characteristics of cell death are considered diagnostic. Therefore, intense research has been conducted using vertebrate cells as a model to identify specific markers of apoptosis which can unequivocally detect early apoptotic cells (Jacobson et al., 1997; Krysko et al., 2008) (Table 1).

In marine invertebrates, apoptosis has been detected by adapting methods developed for cultured vertebrate cells (Seipp et al., 2001; Voronina \& Wessel 2001). More recently, a link between induction of PCD and environmental stress has been established in many marine organisms (Carnevali et al., 2003; Poulet et al., 2003; Romano et al., 2003; Tosti et al., 2003; Ianora et al., 2004; Migliarini et al., 2005; Buttino et al., 2008). 
Table 1 Apoptosis and necrosis signals in cells and methods frequently used to differentiate between apoptosis and necrotic cells

\begin{tabular}{llll}
\hline Morphological and molecular markers & Apoptosis & Detection methods & Necrosis \\
\hline DNA breakage & Early event $(+)$ & TUNEL & Late event or absent $( \pm)$ \\
Chromatin condensation & Present $(++)$ & Hoescht acridine orange & Absent $( \pm)$ \\
Phosphatidylserine exposure & Present $(+)$ & Annexin V & Absent $(-)$ \\
Plasma membrane permeability & Intact $(-)$ & Propidium iodide & Early event $(+)$ \\
Cytoplasmic shrinkage & Present $(+)$ & Microscopy observation & Absent $(-)$ \\
Blebbing (apoptotic bodies) & Present $(+)$ & Microscopy observation & Absent $(-)$ \\
Caspase activation & Present $(+)$ & Enzymatic assays & Absent $(-)$ \\
\hline
\end{tabular}

Here, we review recent progress in the study of induction and detection of apoptosis in zooplankton copepods, after their exposure to different apoptoticinducer compounds, and we propose methods to predict copepod mortality even when organisms appear normal. Moreover, the use of promising microscopy techniques, such as second and third harmonic generation microscopy, are described as new tools to reveal apoptosis in whole-mount animals without the use of fluorescent probes.

\section{Methods to detect apoptotic cells in copepods using fluorescent probes}

Morphological observation of cells in light microscopy (time-lapse imaging using differential interference contrast microscopy DIC) is commonly used as a first screen to differentiate between apoptosis and necrosis. However, the presence of a thin chitinous wall surrounding copepods (embryos, nauplii, and adults) coupled with the opacity of embryos in most species makes analysis of cell morphology in crustaceans very difficult. Therefore, specific fluorescent probes, used to detect apoptosis or necrosis in vertebrate cells, are the only tool to study this process in copepods.

The development of new fluorescent markers that are specific for apoptosis in cultured cells began more than a decade ago (Gavrieli et al., 1992; Sanders 1997; Smith \& Cartwright 1997), and at present, many fluorescent probes are commercially available. Some of these probes have successfully been used to detect PCD or necrosis in marine invertebrates, including sea urchin embryos (Romano et al., 2003), crustaceans (Buttino et al., 2004), and tunicates (Tosti et al., 2003), but these protocols need to be validated for each organism and its life stages.
Among the different probes, vital fluorescent markers are able to detect apoptosis or necrosis in live organisms, while non-vital markers can be used only for fixed samples.

Vital fluorescent probes

\section{Annexin V-FITC}

Annexin V-FITC (fluoresceine isothiocyanate) binds phosphatidyl serine residues that are externalized on the plasma membrane surface during early phases of apoptosis (Aubry et al., 1999; Bossy-Wetzel \& Green, 2000). Therefore, cells undergoing apoptosis appear green in fluorescence. This probe was used to detect apoptotic embryos spawned by the copepod Calanus helgolandicus fed giant liposomes encapsulating known concentrations of a diatom-derived aldehyde (Buttino et al., 2008) (Fig. 2). The protocol involved preliminary permeabilization $(30 \mathrm{~min})$ of the embryonic chitinous wall of the copepod with $1 \mathrm{U} \mathrm{ml}^{-1}$ chitinase enzyme (Buttino et al., 2004). Such incubation did not interfere with normal development of embryos. After rinsing in filtered seawater, embryos were incubated for 30 min with Annexin VFITC (Alexis Biochemicals) at a concentration of $250 \mu \mathrm{ml}^{-1}$. Samples were observed with a Zeiss inverted epifluorescence microscope using a $20 \times$ objective or with a confocal laser scanning microscope.

\section{Annexin V-FITC and propidium iodide}

Poulet et al. (2003) used a double-labeling method to stain $C$. helgolandicus nauplii with Annexin V-FITC coupled with propidium iodide (PI), to simultaneously label apoptotic and necrotic cells in live 

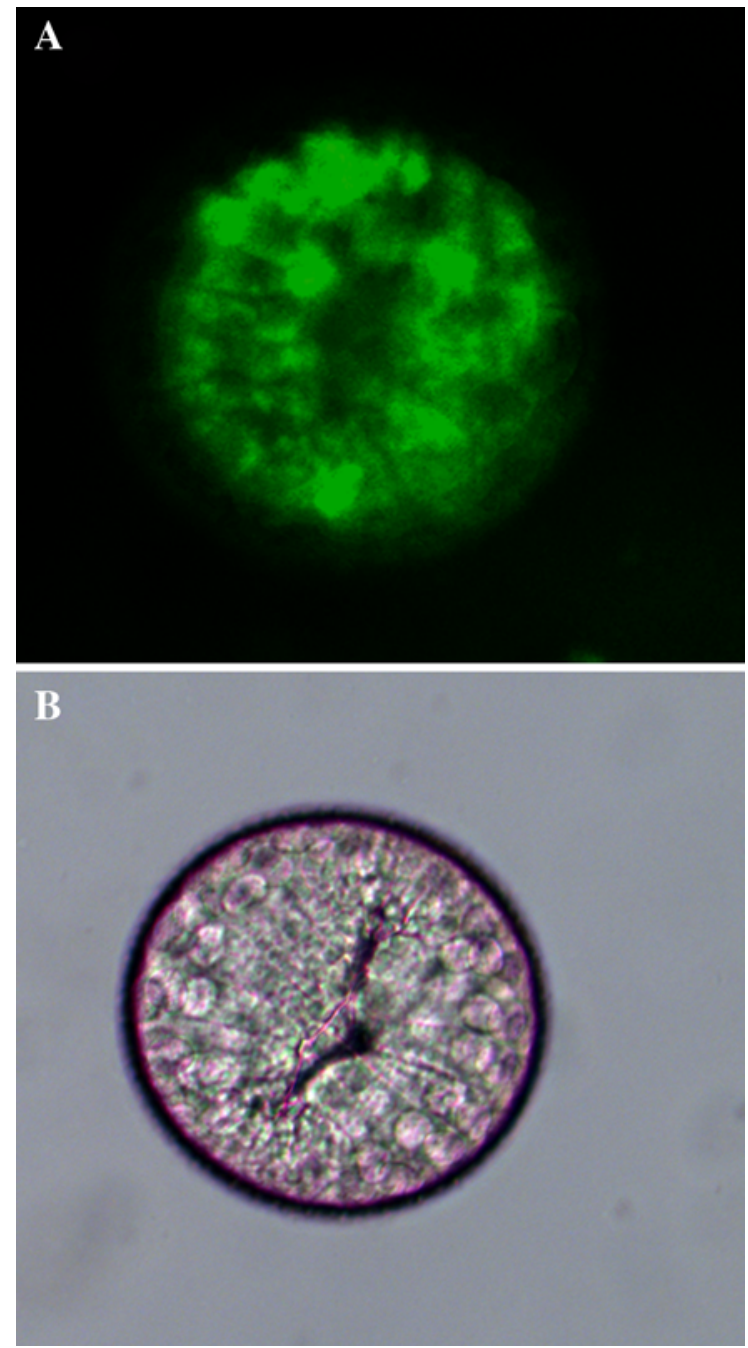

Fig. 2 Calanus helgolandicus embryos stained with Annexin $\mathrm{V}$ to detect apoptosis. A Green fluorescent embryo showing blastomeres positively stained for apoptosis; $\mathbf{B}$ the same as in A observed in transmitted light. Magnification: $\times 200$

copepod nauplii. PI stains nuclei of necrotic cells, which lose their plasma membrane permeability compared to live cells. Dead cells appear with nuclei fluorescent in red (necrotic cells), whereas live cells indicating an early apoptotic process appear fluorescent in green.

Calanus helgolandicus nauplii were not previously permeabilized with chitinase before staining because this treatment was reported to damage live organisms. PI solution was prepared at a concentration of $100 \mu \mathrm{g} \mathrm{ml}^{-1}$ in HEPES buffer (Sigma-Aldrich) according to Ausubel (1998). No more than 30 C. helgolandicus nauplii were incubated in
Eppendorf tubes containing $10 \mu \mathrm{l}$ PI (final concentration of $9 \mu \mathrm{g} \mathrm{ml}^{-1}$ ) and $100 \mu \mathrm{l}$ Annexin- $\mathrm{V}$ for $10 \mathrm{~min}$ at $5^{\circ} \mathrm{C}$ in the dark. Samples were then rinsed in HEPES and fixed with $4 \%$ paraformaldehyde solution for $1 \mathrm{~h}$ at $5^{\circ} \mathrm{C}$ in the dark to prevent bleaching of the fluorescent probe under the laser beam when observed with confocal microscopy (Poulet et al., 2003).

Non-vital fluorescent probes

\section{TUNEL}

Among the classical non-vital fluorescent probes used to detect apoptosis, TUNEL (TdT-mediated dUTP Nick End 225 Labelling) has been successfully used to stain copepod embryos, nauplii, and adults (Romano et al., 2003; Ianora et al., 2004; Buttino et al., 2008). When cells enter apoptosis, lysis of endonucleases trigger the cleavage of DNA into specific oligonucleosomic fragments that are labeled on the free radical $3^{\prime}-\mathrm{OH}$ by a fluorescent marker dUTP using terminal deoxynucleotidyl transferase (TdT) (Iseki \& Mori, 1985; Kaufmann et al., 2000). The labeled nucleotides can be identified histochemically as well as immunocytochemically (as a fluorescent probe) (Gavrieli et al., 1992). At a wavelength of $488 \mathrm{~nm}$, dUTP emits a green fluorescent light which allows detection of apoptotic nuclei that appear green. Simultaneous staining with PI, which marks all nucleic acids red in fixed samples, can be used to confirm that TUNEL green fluorescence is specific for nuclei (Fig. 3). The specificity of this technique for apoptosis is under debate, however, because some studies have reported that TUNEL does not discriminate between necrosis and apoptosis (Graasl-Kraupp et al., 1995; Walker \& Quirke, 2001). Moreover, TUNEL staining is strongly dependent on the type and length of fixation (Negoescu et al., 1996).

To confirm that TUNEL staining in copepod embryos was really due to apoptosis, Romano et al. (2003) coupled this method with DNA laddering. The laddering of ethidium bromide-stained DNA fragments on a gel is one of the classic methods to reveal apoptosis (Compton, 1992; Earnshaw, 1995). The technique consists of the extraction of genomic DNA using a commercial kit (Nuclespin nucleic acid purification kit-Clontech, Palo Alto, CA USA). The total DNA extracted from about 300-800 Calanus 

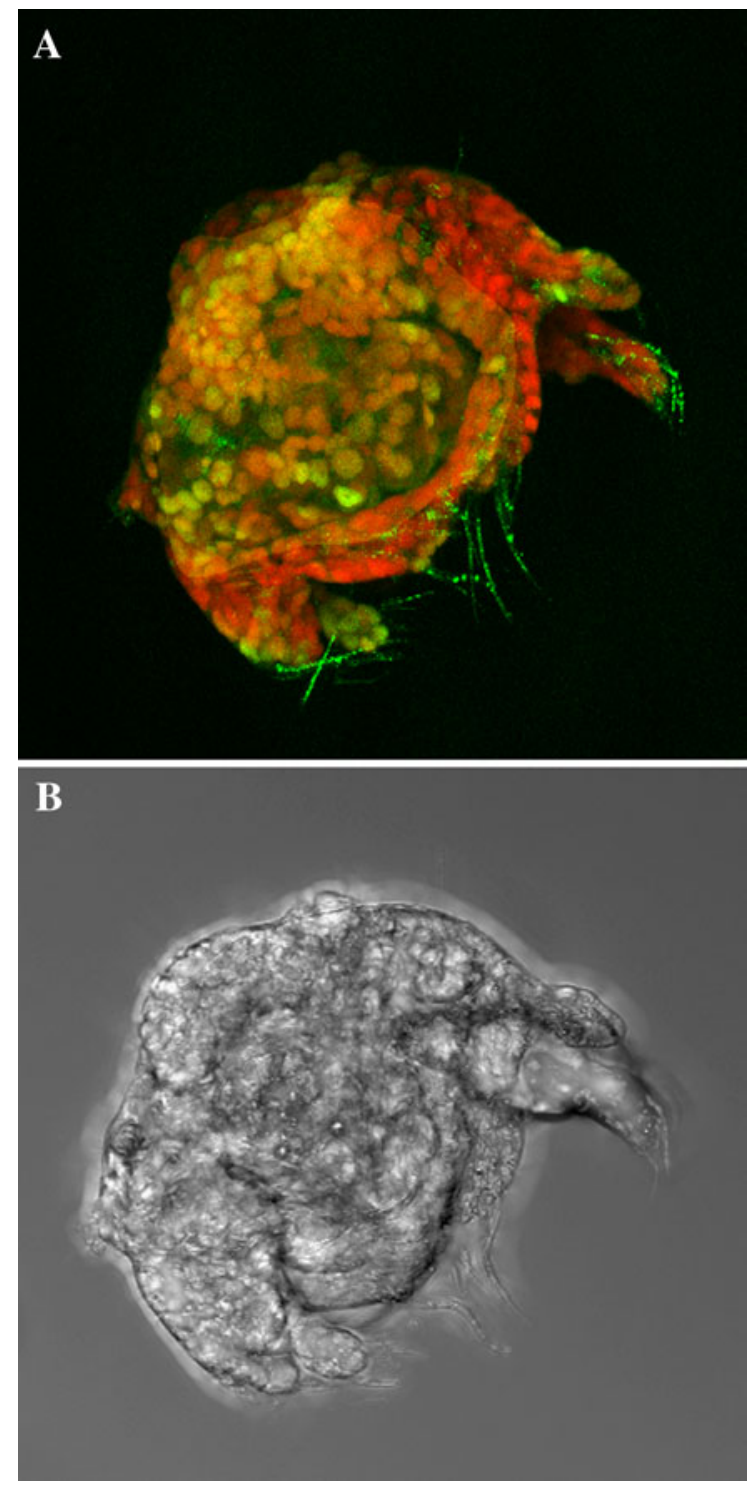

Fig. 3 Calanus helgolandicus nauplius staining with TUNEL and propidium iodide. A Abnormal nauplius produced by female fed 10 days the diatom Skeletonema costatum; yellow spots is a combination of green (TUNEL) and red (PI) fluorescence due to apoptotic nuclei, the red fluorescent cells are not apoptotic, while the green fluorescence are nonspecifically stained cells. Magnification: $\times 200$

helgolandicus was $1-4 \mu \mathrm{g}$, and the amplification of the 16S RNA gene was performed using polymerase chain reaction (PCR) (Bucklin et al., 1995). However, this technique requires a large number of embryos and cannot be recommended for routine screening of apoptosis in copepod embryos.
Before TUNEL staining, both fixed embryos or copepods (adults and nauplii) must be frozen in liquid nitrogen, at least three times, to fracture the carapace (Poulet et al., 2003; Romano et al., 2003; Ianora et al., 2004; Buttino et al., 2008). For larger organisms, such as adults of Calanus helgolandicus, the head may be severed to better permeabilize whole-mount specimens (Buttino et al., 2008). Permeabilization with chitinase solution enzyme follows this treatment.

Recently, to determine specificity and sensitivity of the TUNEL reaction, live staining protocols using Hoechst 33342 to detect apoptosis and PI to detect necrosis have been coupled with TUNEL incubation (Kelly et al., 2003). This protocol has been used successfully on vertebrate cell cultures and whole tissues and may also find applications to detect apoptosis and necrosis in copepods. With this method Kelly et al. (2003) were able to distinguish nuclear condensation, as a result of secondary events, similar to that occurring during apoptosis, also in necrotic cells. With these three labels, the authors demonstrated that TUNEL can underestimate the amount of apoptotic cells or, vice versa, can overestimate apoptosis in the case of a secondary necrotic event.

\section{Second and third harmonic generation microscopy: a new approach to detect apoposis in whole-mount copepods}

Harmonic generation microscopy (HGM) is a laser scanning nonlinear microscopy technique that acquires optical sectioning images with submicron spatial resolution (Chen et al., 2001; Sun et al., 2004). Based on an infrared Cr:forsterite femtosecond laser operating around 1,230 nm, HGM can achieve deep penetration depth and cause little damage compared with commonly used Ti:sapphire lasers (Sun et al., 2004). The corresponding second harmonic generation (SHG) and third harmonic generation (THG) signals fall in the visible wavelength range, making it compatible with microscope optics. In general, THG microscopy can depict the boundaries of cells or the distribution of vesicles. Its signal intensity is determined by the contrast of the refractive index and a material-related constant $\chi^{(3)}$ (Chu et al., 2003; Sun et al., 2004; Liu et al., 2008). 
Second harmonic generation microscopy has been shown to reveal the distribution and orientation of structured proteins such as collagens or microtubules in live zebrafish embryos, while THG has revealed cell membranes and nuclear shape (Sun et al., 2004). This technique allows visualization of structures in in vivo embryos without any invasive protocols. Notwithstanding the high opacity and the thickness of the sample ( $>1 \mathrm{~mm}$-thick), cellular and subcellular structures in zebrafish embryos have been observed with excellent 3D resolution and in depth (Sun et al., 2004). Moreover, strong THG signals were recently found associated to the apoptotic bodies in the hind brain of zebrafish. The same apoptotic bodies were positively stained with acridine orange and detected by 2-Photon fluorescence microscopy (Chen et al., 2006; Hsieh et al., 2008). These techniques have never been tested on copepods until now. We are currently exploring the possible use of two photon and HG microscopy to detect apoptosis in copepods, without using any fluorescent probes (data not shown).

In our preliminary experiments (unpublished data) THG signals increase in apoptotic nauplii, as demonstrated in zebrafish embryo (Chen et al., 2006; Hsieh et al., 2008). If these results are confirmed in further studies, this non-invasive technique can be used to predict naupliar mortality without using fluorescent probes. This approach could have interesting applications for future in vivo studies, such as detecting toxicity before acute or chronic effects become apparent in animals collected in polluted sites.

\section{Concluding remarks}

Studies on apoptosis in copepods are relatively new and methods to detect apoptosis may be useful to predict copepod death at an early stage in the marine environment. It is clear that accurate screening of programmed cell death at the cellular level (apoptosis), or in whole organisms (phenopthosis) is only possible through an integrated approach based on several morphological and biochemical observations. No single technique is adequate to unequivocally demonstrate apoptosis, and different complementary methods must be applied for any individual model.

The list of probes able to discriminate apoptotic and necrotic cells described here is focused on those recently used on copepods (organisms and embryos) in our laboratory. Other viable probes, such as Hoechst (Hardin et al., 1992; Telford et al., 1992; Camby et al., 1995) and Acridine Orange (Tucker \& Lardelli 2007) have been used to detect apoptosis in other animal models and their application to reveal apoptosis in copepods need to be tested. Moreover, vital fluorescent probes such as Fluoresceine Diacetate or its homologous Sytox green and 7-aminoactinomycin (7-AAD) have been used to discriminate between live or death cells in copepods but they were not able to differentiate between necrosis and apoptosis even if they can be useful to rapidly detect copepod embryo viability without having to wait for eggs to hatch (Buttino et al., 2003, 2004).

In the future, new non-invasive second and third harmonic generation microscopy coupled with 2 photon microscopy that has already been applied to other marine organisms, may become useful to detect apoptosis in live or fixed copepods without using fluorescent probes.

Acknowledgments This research has partially been supported by the National Health Research Institute of Taiwan, through grant NHRI-EX98-9201EI, by the National Science Council of Taiwan, through grant NSC 98-2112-M002-022 and by the bilateral project SZN-NSC grant NSC 992923-B-019-001-MY2. Special thanks are due to Mario Di Pinto for his technical support.

\section{References}

Aubry, J. P., A. Blaeckem, S. Lecoanet-Henchoz, P. Jeannin, N. Herbault, G. Caron, V. Moine \& J. Y. Bonnefoy, 1999. Annexin-V used for measuring apoptosis in the early events of cellular cytotoxicity. Cytometry 37: 197-204.

Ausubel, F. M., 1998. Current protocols in molecular biology. Molecular biology-technique. Molecular biology-laboratory manual. Wiley, New York.

Behilarz, E. J., C. E. Williams, M. Dragunow, E. S. Sirimanne \& P. D. Gluckman, 1995. Mechanisms of delayed cell death following hypoxic-ischemic injury in the immature rat: evidence for apoptosis during selective neuronal loss. Molecular Brain Research 29: 1-14.

Bossy-Wetzel, E. \& D. R. Green, 2000. Detection of apoptosis by Annexin V labelling. In Reed, J. C. (ed.), Methods in Enzymology. Academic, San Diego: 15-18.

Bucklin, A., B. W. Frost \& T. D. Kocher, 1995. Molecular systematic of six Calanus and three Metridia species (Calanoida: Copepoda). Marine Biology 121: 655-664.

Buttino, I., A. Ianora, Y. Carotenuto \& A. Miralto, 2003. Use of the confocal laser scanning microscope in studies on the developmental biology of marine crustaceans. Microscopy Research and Techniques 60: 458-464. 
Buttino, I., M. do Espirito Santo, A. Ianora \& A. Miralto, 2004. Rapid assessment of copepod embryo viability using fluorescent probes. Marine Biology 145: 393-399.

Buttino, I., G. De Rosa, Y. Carotenuto, M. Mazzela, A. Ianora, F. Esposito, V. Vitiello, F. Quaglia, M. I. La Rotonda \& A. Miralto, 2008. Aldehyde-encapsulating liposomes impair marine grazer survivorship. Journal of Experimental Biology 211: 1426-1433.

Caldwell, G. S., 2009. The influence of bioactive oxylipins from amrine diatoms on invertebrate reproduction and development. Marine Drugs 7: 367-400.

Camby, I., I. Salmon, A. Danguy, J. L. Pasteels \& R. Kiss, 1995. The use of the digital cell image analysis of Feulgen-stained nuclei to detect apoptosis. Histochemistry and Cell Biology 104: 407-414.

Carnevali, O., V. Polzonetti, M. Cardinali, A. Pugnaloni, P. Natalini, N. Zmora, G. Mosconi \& A. M. PolzonettiMagni, 2003. Apoptosis in sea bream Sparus aurata eggs. Molecular Reproduction and Development 9999: 1-6.

Chen, I.-H., T.-M. Liu, P.-C. Cheng, C.-K. Sun \& B.-L. Lin, 2001. Multimodal nonlinear spectral microscopy based on a femtosecond Cr:forsterite laser. Optics Letters 26: 1909-1911.

Chen, S.-Y., C.-S. Hsieh, S.-W. Chu, C.-H. Lin, C.-Y. Ko, Y.- C. Chen, H.-J. Tsai, C.-H. Hu \& C.-K. Sun, 2006. Non invasive harmonics optical microscopy for long-term observation of embryonic nervous system development in vivo. Journal of Biomedical Optics 11: 054022-1-054022-8.

Chu, S.-W., S.-Y. Chen, T.-H. Tsai, T.-M. Liu, C.-Y. Lin, H.-J. Tsai \& C.-K. Sun, 2003. In vivo developmental biology study using non invasive multi-harmonic generation microscopy. Optics Express 11: 3093-3099.

Compton, M. M., 1992. A biochemical hallmark of apoptosis, internucleosomal degradation of the genome. Cancer Metastasis Reviews 11: 105-119.

Depont, M., 2008. Programmed cell death in protists. Biochemical and Biophysical Acta 1783: 1396-1405.

Earnshaw, W. C., 1995. Nuclear changes in apoptosis. Current Opinion in Cell Biology 7: 337-343.

Gadjev, I., J. M. Stone \& T. S. Gechev, 2008. Programmed cell death in plants: new insights into redox regulation and the role of hydrogen peroxide. International Review of Cell and Molecular Biology 270: 87-144.

Gavrieli, Y., Y. Sherman \& S. A. Ben-Sasson, 1992. Identification of programmed cell death in situ via specific labeling of nuclear DNA fragmentation. The Journal of Cell Biology 119: 493-501.

Graasl-Kraupp, B., B. Ruttkay-Nedecky, H. Koudelka, K. Bukowska, W. Bursch \& R. Schulte-Hermann, 1995. In situ detection of fragment DNA (TUNEL assay) fails to discriminate among apoptosis, necrosis, and autolytic cell death: a cautionary note. Hepatology 21: 1465-1468.

Hamman, A., D. Brust \& H. D. Osiewacz, 2008. Apoptosis pathways in fungal growth, development and ageing. Trends in Microbiology 16: 276-283.

Hardin, J. A., D. H. Sherr, M. DeMaria \& P. A. López, 1992. A simple fluorescence method for surface antigen phenotyping of lymphocytes undergoing DNA fragmentation. Journal of Immunological Methods 154: 99-107.

Hsieh, C.-S., C.-Y. Ko, S.-Y. Chen, T.-M. Liu, J.-S. Wu, C.-H. $\mathrm{Hu} \&$ C.-K. Sun, 2008. In vivo long-term continuous observation of gene expression in zebrafish embryo nerve systems by using harmonic generation microscopy and morphant technology. Journal of Biomedical Optics 13: 064041-1-064041-7.

Ianora, A. \& S. A. Poulet, 1993. Egg viability in the copepod Temora stylifera. Limnology and Oceanography 38: 1615-1626.

Ianora, A., S. A. Poulet \& A. Miralto, 2003. The effects of diatoms on copepod reproduction: a review. Phycologia 42: $351-363$.

Ianora, A., A. Miralto, S. A. Poulet, Y. Carotenuto, I. Buttino, G. Romano, R. Casotti, G. Pohnert, T. Wichard, L. Colucci-D'Amato, G. Terrazzano \& V. Smetacek, 2004. Aldehyde suppression of copepod recruitment in blooms of a ubiquitous planktonic diatom. Nature 429: 403-407.

Iseki, S. \& T. Mori, 1985. Histochemical detection of DNA strand scissions in mammalian cells by in situ nick translation. Cell Biology International Report 9: 471-477.

Jacobson, M., M. Weil \& M. Raff, 1997. Programmed cell death in animal development. Cell 88: 347-354.

Kaufmann, S. H., P. W. Mesner, K. Samejima, S. Toné \& W. C. Earnshaw, 2000. Detection of DNA cleavage in apoptotic cells. In Reed, J. C. (ed.), Methods in Enzymology, Apoptosis. Academic, San Diego: 3-11.

Kelly, K. J., M. R. Sandoval, K. W. Dunn, B. A. Molitoris \& P. C. Dagher, 2003. A novel method to determine specificity and sensitivity of the TUNEL reaction in the quantitation of apoptosis. American Journal Physiology-Cell Physiology 284: 1309-1318.

Krysko, D. V., T. V. Berghe, K. D’Herde \& P. Vandenabeele, 2008. Apoptosis and necrosis: detection, discrimination and phagocytosis. Methods 44: 205-221.

Leist, M. \& P. Nicotera, 1997. The shape of cell death. Biochemical and Biophysical Research Communications 236: 1-9.

Liu, T.-M., Y.-W. Lee, C.-F. Chang, S.-C. Yeh, C.-H. Wang, S.-W. Chu \& C.-K. Sun, 2008. Imaging polyhedral inclusion bodies of nuclear polyhedrosis viruses with second harmonic generation microscopy. Optics Express 16: 5602-5608.

Migliarini, B., A. M. Campisi, F. Maradonna, C. Truzzi, A. Annibaldi, G. Scarponi \& O. Carnevali, 2005. Effects of cadmium exposure on testis apopotosis in the marine teleost Gobius niger. General and Comparative Endocrinology 142: 241-247.

Miralto, A., G. Barone, G. Romano, S. A. Poulet, A. Ianora, L. Russo, I. Buttino, G. Mazzarella, M. Laabir, M. Cabrini \& M. G. Giacobbe, 1999. The insidious effect of diatoms on copepod reproduction. Nature 402: 173-176.

Miralto, A., L. Guglielmo, G. Zagami, I. Buttino, A. Granata \& A. Ianora, 2003. Inhibition of population growth in the copepods Acartia clausi and Calanus helgolandicus during diatom blooms. Marine Ecology Progress Series 254: 253-268.

Negoescu, A., P. Lorimier, F. Labat-Moleur, C. Drouet, C. Robert, C. Guillermet, C. Brambilla \& E. Brambilla, 1996. In situ apoptotic cell labeling by the TUNEL method: improvement and evaluation on cell preparations. Journal of Histochemistry and Cytochemistry 44: 959-968.

Pohnert, G., M. Steinke \& R. Tollrian, 2007. Chemical cues, defence metabolites and the shaping of pelagic interspecific interactions. Trends in Ecology and Evolution 22: 198-204. 
Poulet, S. A., A. Ianora, A. Miralto \& L. Meijer, 1994. Do diatoms arrest egg development in copepods? Marine Ecology Progress Series 111: 79-86.

Poulet, S. A., M. de Richer Forges, A. Cueff \& J. F. Lennon, 2003. Double-labelling methods used to diagnose apoptotic and necrotic cell degradations in copepod nauplii. Marine Biology 143: 889-895.

Rastogi, R. P., R. Richa \& R. P. Sinha, 2009. Apoptosis: molecular mechanisms and pathogenicity. Excli Journal 8: 155-181.

Romano, G., G. L. Russo, I. Buttino, A. Ianora \& A. Miralto, 2003. A marine diatom derived aldehyde induces apoptosis in copepod and sea urchin embryos. Journal of Experimental Biology 206: 3487-3494.

Sanders, E. J., 1997. Methods for detectin apoptotic cells in tissues. Histology and Histopathology 12: 1169-1177.

Seipp, S., J. Schmich \& T. Leitz, 2001. Apoptosis-a deathinducing mechanism tightlylinked with morphogenesis in Hydractina echinata (Cnidaria, Hydrozoa). Development 128: 4891-4898.

Smith, S. M. \& M. M. Cartwright, 1997. Spatial visualization of apoptosis using a whole-mount in situ DNA endlabeling technique. Biothechniques 22: 832-833.

Sun, C.-K., S.-W. Chu, S.-Y. Chen, T.-H. Tsai, T.-M. Liu, C.H. Lin \& H.-J. Tsai, 2004. Higher harmonic generation microscopy for developmental biology. Journal of Structural Biology 147: 19-30.

Telford, W. G., L. E. King \& P. J. Fraker, 1992. Comparative evaluation of several DNA binding dyes in the detection of apoptosis-associated chromatin degradation by flow cytometry. Cytometry 13: 137-143.

Tosti, E., G. Romano, I. Buttino, A. Cuomo, A. Ianora \& A. Miralto, 2003. Bioactive aldehydes from diatoms block fertilization currents in ascidian oocytes. Molecular Reproduction and Development 66: 72-80.

Tucker, B. \& M. Lardelli, 2007. A rapid apoptosis assay measuring relative acridine orange fluorescence in zebrafish embryos. Zebrafish 4: 113-116.

Voronina, E. \& G. M. Wessel, 2001. Apoptosis in sea urchin oocytes, eggs, and early embryos. Molecular Reproduction and Development 60: 553-561.

Walker, J. A. \& P. Quirke, 2001. Viewing apoptosis through a “Tunel". Journal of Pathology 195: 275-276.

Williams, G. T., 1991. Programmed cell death: apoptosis and oncogenesis. Cell 65: 1097-1098.

Yuan, J., S. Shaham, S. Ledoux, H. M. Ellis \& R. H. Horvitz, 1993. The $C$. elegans cell death gene ced-3 encodes a protein similar to mammalian interleukin- $1 \beta$-converting enzyme. Cell 75: 641-652. 